\title{
Unresectable Urethral Urothelial
} Carcinoma

National Cancer Institute

\section{Source}

National Cancer Institute. Unresectable Urethral Urothelial Carcinoma. NCI Thesaurus.

Code C158585.

Urethral urothelial carcinoma that is not amenable to surgical resection. 